\title{
PROSPEK PENGEMBANGAN CABAI RAWIT DI KECAMATAN ARUT SELATAN KABUPATEN KOTAWARINGIN BARAT
}

\section{PROSPECT OF DEVELOPMENT OF CAYANNE PEPPER IN THE SUB-DISTRIC OF ARUT SELATAN KOTAWARINGIN BARAT REGENCY}

\author{
Novi Nurhayati \\ Prodi Agribisnis, Fakultas Pertanian, Universitas Antakusuma \\ Jl. Iskandar No 63 Kode pos 74112 Pangkalan Bun \\ Novinurhayatiuntama78@yahoo.com
}

\begin{abstract}
ABSTRAC
The purpose of this research is to know the analysis of chili pepper farming farming and prospect of cayenne pepper development in the sub distric of Arut Selatan Kotawaringin Barat regency. Analysis of cayenne pepper includes income analysis, acceptan, , revenue cost ratio, Break even poin price, break even poin productioni, return on investment. The prospect of chili pepper development can be known by the strengths, weaknesses, opportunities and threats. The data needed in this study are secondary data and primary data variabel cost, fixed cost, price and quantity of production. Pursuant to result of research of cayenne pepper farm have value of acceptance equal to Rp. 11.723.333,33.,; income equal to Rp. 5.618.333,33.,; revenue cost ratio equal to 1.90; break even poin production equal to $124,14 \mathrm{~kg}$; break even poin price equal to $\mathrm{Rp}$. $26.038,27$ and return on investment equal to $90,25 \%$. The prospect of the development of chili pepper farm has a good prospect, because based on SWOT analysis is in quadrant I which means very profitable for a business, which has the streanght and the chances of mutual support.
\end{abstract}

Keywords : Prospect of cayenne pepper development

\begin{abstract}
ABSTRAK
Tujuan dari penelitian ini adalah untuk mengetahui analisis usahatani cabai rawit dan prospek pengembangan usahatani cabai rawit di Kecamatan Arut Selatan Kabupaten Kotawaringin Barat. Analisis usahatani cabai rawit ini meliputi analisis pendapatan, penerimaan, revenue cost ratio, Break even poin harga, break even poin produksi, return on investment. Prospek pengembangan cabai rawit dapat diketahui dengan mengetahui kekuatan, kelemahan, peluang dan ancaman. Data yang diperlukan dalam penelitian ini adalah data sekunder dan data primer yang meliputi biaya tetap, biaya tidak tetap, harga, dan jumlah produksi. Berdasarakan hasil penelitian usahatani cabai rawit mempunyai nilai penerimaan sebesar Rp. 11.723.333,33.,; pendapatan sebesar Rp. $5.618 .333,33 .$, revenue cost ratio sebesar 1.90; break even poin produksi sebesar $124,14 \mathrm{~kg}$; break even poin harga sebesar Rp. 26.038,27 dan return on investment sebesar 90,25\%. Prospek pengembangan usahatani cabai rawit mempunyai prospek yang bagus, karena berdasarkan analisis SWOT berada pada kuadran I yang berarti sangat menguntungkan bagi suatu usaha, dimana mempunyai kekuatan dan peluang yang saling mendukung.
\end{abstract}

Kata Kunci : Prospek Pengembangan Usahatani Cabai Rawit

\section{PENDAHULUAN}

\subsection{Latar Belakang}

Tanaman cabai (Capsicum annum L)

merupakan salah satu komoditas sayuran, yang umumnya digunakan sebagai bumbu masakan yang dikonsumsi dalam bentuk segar. Dalam penggunaannya sebagai bumbu masakan dengan jumlah yang sedikit, akan tetapi terjadi 
ketidakseimbangan antara penawaran dan permintaan buah cabai, yang mengakibatkan terjadinya selalu berfluktuasinya harga buah cabai.

Pada saat-saat tertentu, harganya buah cabai dapat naik berlipat-lipat dari harga sebelumnya. Hal ini membuat budidaya tanaman cabai menjadi tantangan tersendiri bagi para petani. Disamping fluktiasi harga, budidaya cabai cukup rentan dengan kondisi cuaca dan serangan hama. Untuk meminimalkan semua resiko tersebut, biaya untuk budidaya cabai bisa dikatakan cukup tinggi. Berikut adalah gambaran fluktuasi harga buah cabai di Kabupaten Kotawaringin Barat Pada Tahun 2014-2015.

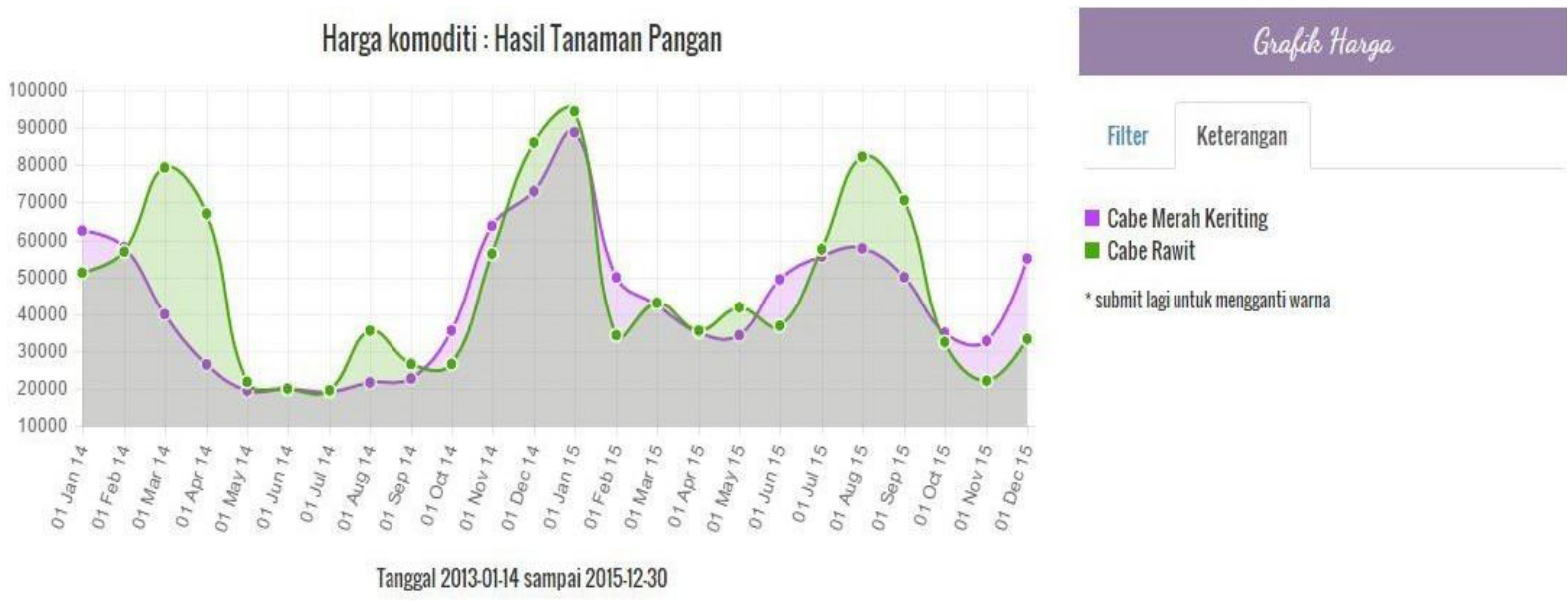

Sumber : Dinas Perindustrian dan Perdagangan, Tahun 2015

Gambar : Fluktuasi Harga Cabai di Kabupaten Kotawaringin Barat Tahun 2014-2015

Dalam rangka pengembangan budidaya tanaman cabai, perlu dilakukan pengaturan pola tanam sesuai dengan permintaan serta pengembangan teknologi yang maju untuk mendukung peningkatan produktivitas tanaman cabai. Menurut Badan Pusat Statistik (BPS) (2016), luas panen tanaman cabai yang terdapat di Kabupaten
Kotawaringin Barat yang terdiri dari Kecamatan Kotawaringin Lama, Kecamatan Arut Selatan, Kecamatan Kumai, Kecamatan Pangkalan Banteng, Kecamatan Pangkalan Lada dan Kecamatan Arut Utara adalah seluas 163 ha dengan jumlah produksi sebanyak 389,5 ton. Lebih jelasnya dapat dilihat pada Tabel 1 dibawah ini.

Tabel 1. Luas Panen dan Produksi Buah Cabai di Kabupaten Kotawaringin Barat Pada Tahun 2015.

\begin{tabular}{|r|l|c|r|}
\hline \multirow{2}{*}{ No } & \multirow{2}{*}{ Kecamatan } & \multicolumn{2}{|c|}{ Cabai Rawit } \\
\cline { 3 - 4 } & & Luas Panen (Ha) & \multicolumn{1}{|c|}{ Produksi (ton) } \\
\hline 1 & Kotawaringin Lama & 11 & 32,2 \\
\hline 2 & Arut selatan & 42 & 108,4 \\
\hline 3 & Kumai & 21 & 32,2 \\
\hline 4 & Pangkalan Banteng & 38 & 104,7 \\
\hline 5 & Pangkalan Lada & 39 & 106,3 \\
\hline
\end{tabular}




\begin{tabular}{|r|l|c|r|}
\hline 6 & Arut Utara & 12 & 5,7 \\
\hline & Jumlah & 163 & 389,5 \\
\hline
\end{tabular}

Sumber : Badan Pusat Statistik Kotawaringin Barat 2016

Berdasarkan pada Tabel 1, diatas dapat

dilihat bahwa produksi buah cabai selama

Tahun 2015 adalah sebesar 389,5 ton.

Produksi paling banyak adalah Kecamatan

Arut Selatan dengan jumlah 108, 4 ton, diikuti

Kecamatan Pangkalan Lada dengan jumlah

106,3 ton, Kecamatan Pangkalan Banteng dengan jumlah 104,7 ton, Kecamatan Kumai dan Kecamatan Kotawaringin lama dengan jumlah 32,2 ton dan yang terakhir adalah Kecamatan Arut Utara dengan jumlah 5,7 ton. Produksi buah cabai di Kabupaten Kotawaringin Bara, belum dapat memenuhi permintaan pasar, sehingga harga buah cabai dipasar semakin meningkat. Pada Bulan Januari 2017 harga cabai mencapai puncaknya $\begin{array}{lll}\text { yaitu } & \mathrm{Rp} . & 150.000 ., \mathrm{kg}\end{array}$ (https://www.harianidn.com). Padahal sebelumnya pada Bulan November Tahun 2016 harga buah cabai dipasaran hanya mencapai Rp.75.000/kg (http://www.borneonews.co.id). Kenaikan harga buah cabai yang sangat fantastis ini, membuat masyarakat gelisah baik dari sisi pedagang maupun dari sisi konsumennya.

Dari permasalahan-permasalahan yang ada, peneliti ingin mengetahui bagaimana analisis usaha tanaman cabai ini, apakah menguntungkan atau tidak. Dengan mengetahui analisis usahanya, sehingga dapat digunakan untuk mengetahui bagaimana prospek pengembanngan budidaya tanaman cabai di kecamatan Arut Selatan.

\subsection{Tujuan Penelitian}

Tujuan penelitian ini adalah untuk mengetahui :

1. Analisis usahatani tanaman cabai di Kecamatan Arut Selatan Kabupaten Kotawaringin Barat.

2. Strategi dan prospek pengembangan budidaya tanaman cabai di Kecamatan Arut Selatan Kabupaten Kotawaringin Barat.

\section{METODOLOGI PENELITIAN}

\subsection{Tempat dan Waktu Penelitian}

Penelitian ini dilaksanakan di

Kecamatan Arut Selatan Kabupaten

Kotawaringin Barat pada Bulan April

sampai Juni Tahun 2017.

\subsection{Jenis dan Sumber Data}

Jenis data yang digunakan dalam penelitian ini adalah data sekunder dan data primer. Data sekunder bersumber dari Badan Pusat Statistik, Dinas Perindustrian dan Perdagangan, Dinas Ketahanan Pangan, Dinas Tanaman Pangan, Hortikultura dan Tanaman Perkebunan. Data primer bersumber dari quisioner yang dibagikan kepada petani.

\subsection{Teknik Pengambilan Sampel}

Teknik dalam pengambilan sampel dalam penelitian ini adalah dengan metode random sampling. Jumlah petani yang 
diambil sebagai responden adalah sebanyak 60 petani.

\subsection{Analisis Data}

Analis data yang digunakan dalam penelitian ini adalah :

1. Untuk menjawab tujuan yang pertama yaitu mengetahui analisis usahatani cabai, menggunakan rumus sebagai berikut :

a. Pendapatan petani sayur dihitung dengan menggunakan rumus :

$$
\pi=T R-T C
$$$$
\mathbf{T R}=\mathbf{Q} . \mathbf{P q}
$$

$$
\mathbf{T C}=\mathbf{T V C}+\mathbf{T F C}
$$

Dimana :

$\pi=$ pendapatan petani cabai

$\mathrm{TR}=$ Total penerimaan usahatani cabai ke-i (Rp)

$\mathrm{Q}=$ Jumlah produksi cabai $(\mathrm{Kg})$

$\mathrm{Pq}=$ Harga cabai $(\mathrm{Rp})$

$\mathrm{TC}=$ Total Cost/total biaya produksi cabai

TVC $=$ total variabel Cost $/$ Total

Biaya Variabel cabai

TFC $=$ Total Fixed Cost/Total

biaya pasti cabai b. Return Cost Ratio ( $R / C$ ratio), dihitung dengan mengunakan rumus :

$\mathrm{RC}=\mathrm{TR} / \mathrm{TC}$

c. Produktivitas Modal, dihitung dengan menggunakan rumus :

Produktivitas Modal $=\pi / \mathrm{TC}$

d. Break Even Point (BEP), dihitung dengan menggunakan rumus : $\mathrm{BEP}=\frac{T F C}{P q-\frac{T V C}{Q}}$

2. Untuk menjawab tujuan yang kedua, yaitu prospek pengembangan tanaman cabai menggunakan analisi SWOT.

Analisa SWOT membandingkan antara faktor eksternal peluang dan ancaman dengan faktor internal kekuatan dan kelemahan faktor internal dimasukan kedalam matrik yang disebut matrik faktor strategi internal atau IFAS (internal strategic factor analisis summary). Faktor eksternal dimasukan kedalam matrik yang disebut matrik faktor strategi ekstrnal EFAS (ekstrnal strategic factor analisis summary).

Tabel 2. Matrik Faktor Strategi Internal (IFAS)

\begin{tabular}{|l|l|l|c|}
\hline Faktor Strategi Internal & Bobot & Rating & Bobot X Rating \\
\hline Keluatan & & & \\
\hline 1. & & & \\
\hline 2. & $\mathrm{a}$ & & $\mathrm{b}$ \\
\hline Jumlah &
\end{tabular}




\begin{tabular}{|l|c|l|c|}
\hline Kelemahan & & & \\
\hline 1. & & & \\
\hline 2. & $c$ & & $\mathrm{~d}$ \\
\hline Jumlah & $(\mathrm{a}+\mathrm{c})=1$ & & $(\mathrm{~b}+\mathrm{d})$ \\
\hline Total &
\end{tabular}

Tabel 2. Matrik Faktor Strategi Eksternal (EFAS)

\begin{tabular}{|l|c|l|l|}
\hline \multicolumn{1}{|c|}{ Faktor Strategi Eksternal } & Bobot & Rating & Bobot X Rating \\
\hline Peluang & & & \\
\hline 1. & & & \\
\hline 2. & $\mathrm{a}$ & & $\mathrm{b}$ \\
\hline Jumlah & & & \\
\hline Ancaman & & & \\
\hline 1. & $\mathrm{c}$ & & $\mathrm{d}$ \\
\hline 2. & $(\mathrm{a}+\mathrm{c})=1$ & & $(\mathrm{~b}+\mathrm{d})$ \\
\hline Jumlah &
\end{tabular}

Setelah mengetahui faktor strategi internal dan eksternal, dan menyusunnya dalam tabel IFAS dan EFAS. Langkah selanjutnya adalah memberikan nilai bobot dan rating, dengan cara sebagai berikut :

1. Memberikan bobot masing-masing faktor pada kolom 2, mulai dari 1,0 (sangat penting) sampai dengan 0,0 (tidak penting). Bobot dari semua faktor strategis yang berupa peluang dan ancaman ini harus berjumlah 1 .

2. Menghitung rating dalam (dalam kolom 3) untuk masing-msing faktor dengan memberi skala mulai dari 4 (sangat baik/outstanding) sampai dengan 1 (sangat tidak baik/poor) berdasarkan pengaruh faktor tersebut pada kondisi organisasi. Pemberian nilai rating untuk peluang bersifat positif, artinya peluang yang semakin besar diberi rating +4 , tetapi jika peluangnya kecil diberi nilai
+1 . Sementara untuk rating ancaman bersifat sebaliknya, yaitu jika nilai ancamannya besar, maka ratingnya -4 dan jika nilai ancamannya kecil, maka nilainya -1 .

3. Mengalikan bobot faktor pada kolom 2 dengan rating pada kolom 3. Hasilnya adalah skor pembobotan untuk masingmasing faktor.

4. Menghitung jumlah skor pembobotan. Nilai ini adalah untuk memetakan posisi organisasi pada diagram analisa SWOT.

5. Setelah dapat perhitungan Bobot dan Rating maka untuk menentukan diagram analisis SWOT dapat dihitung dengan menggunakan rumus :

a. $\mathrm{S}-\mathrm{W}$ (selisih antara strengths dengan weakness) sebagai sumbu $\mathrm{X}$ adalah kuadran strategi. 
b. $\mathrm{O}-\mathrm{T}$ (selisih antara opportunities dalam kuadran strategi. dengan threats) sebagai sumbu $\mathrm{Y}$

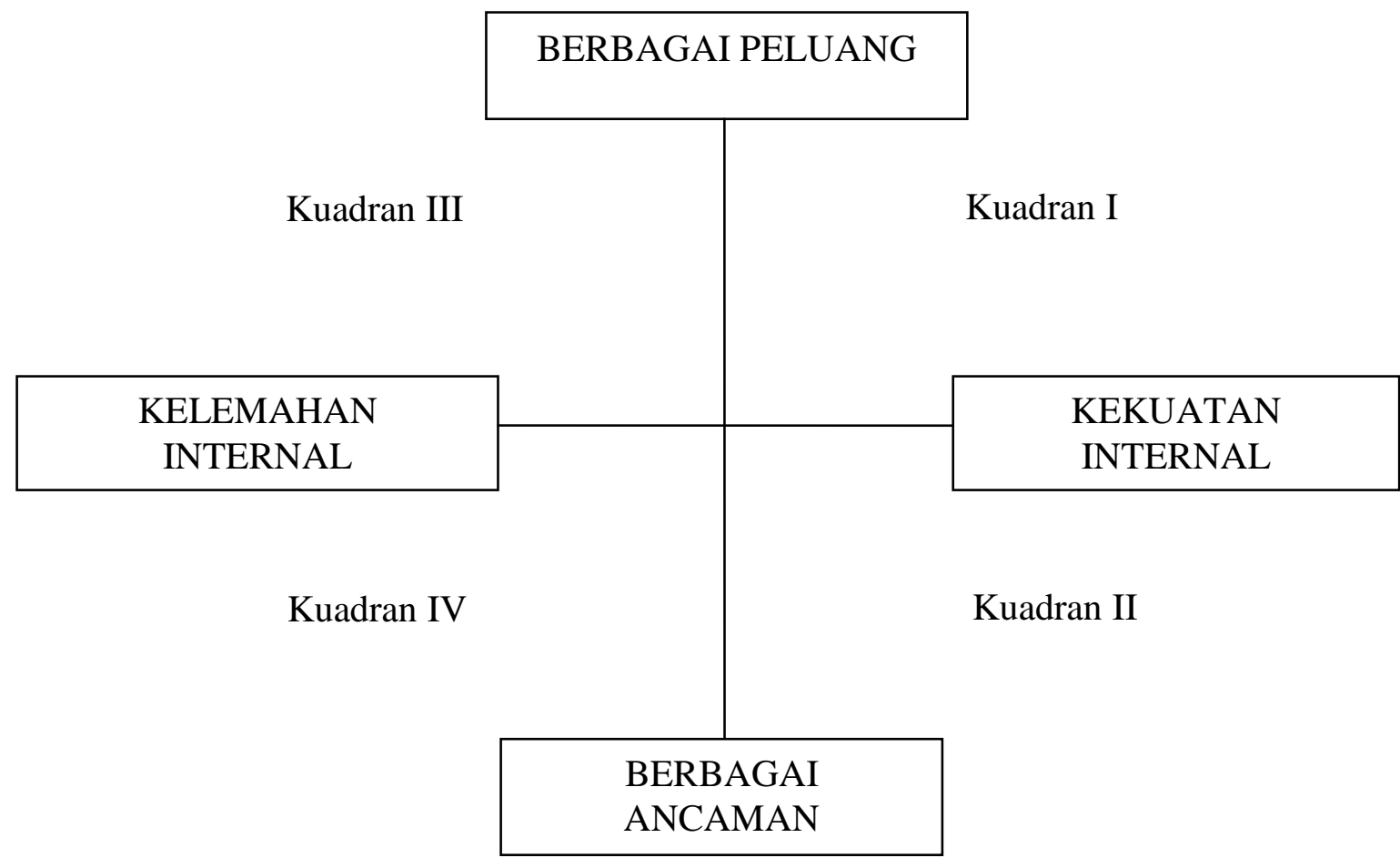

Gambar 02. Diagram Analisa SWOT

- Kuadran I : ini merupakan situasi yang sangat menguntungkan bagi perusahaan. Perusahaan tersebut memiliki peluang dan kekuatan yang sangat besar sehingga dapat memanfaatkan peluang yang ada. Strategi yang harus diterapkan dalam kondisi ini adalah mendukung kebijakan pertumbuhan yang agresif (Growth oriented strategy).

- Kuadran II : meskipun menghadapi berbagai ancaman, perusahaan ini masih memiliki kekuatan dari segi internal. Strategi yang harus di terapkan adalah dengan menggunakan kekuatan untuk memanfaatakn peluang jangka panjang dengan strategi diversifikasi (produk atau pasar).
- Kuadran III : Perusahaan menghadapi peluang pasar yang sangat besar, tetapi dilain pihak juga menghadapi beberapa kendala/kelemahan internal. Fokus strategi perusahaan ini adalah meminimalkan masalah-masalah internal perusahaan sehingga dapat merebut peluang pasar yang lebih baik.

- Kuadran IV : Kondisi ini sangat tidak menguntungkan, perusahaan menghadapi berbagai ancaman dan kelemahan internal.

\section{PEMBAHASAN}

\subsection{Hasil dan Pembahasan}

\subsubsection{Analisis Usahatani Cabai Rawit}


Usahatani cabai rawit mempunyai tujuan utama yaitu untuk mendapatkan hasil yang maksimal dengan menggunakan faktor produksi seoptimal mungkin. Didalam usahatani cabai ini rekapitulasi biaya yang dikeluarkan harus diperhitungkan sebagai biaya oleh pengelola usaha tani, karena dengan diketahui biaya dan penerimaan seorang petani dapat memperkirakan apakah usahatani yang dilakukan untung atau rugi. Berikut adalah hasil analisis usahatani cabai rawit di Kecamatan Arut Selatan :

Tabel 3. Hasil Analisis Usahtani Cabai Rawit Di Kecamatan Arut Selatan Kabupaten Kotawaringin Barat Tahun 2017

\begin{tabular}{|c|l|r|}
\hline No. & \multicolumn{1}{|c|}{ Uraian } & Nilai \\
\hline 1. & Biaya tetap & $2.014 .650,00$ \\
\hline 2. & Biaya tidak tetap & $4.090 .350,00$ \\
\hline 3. & Biaya total & $6.105 .000,00$ \\
\hline 4. & Harga per kg & $49.000,00$ \\
\hline 5. & Produksi & 238,06 \\
\hline 6. & Penerimaan & $11.723 .333,33$ \\
\hline 7. & Pendapatan & $5.618 .333,33$ \\
\hline 8. & R/C & 1,90 \\
\hline 9. & BEP Harga & $26.038,67$ \\
\hline 10. & BEP Produksi & 124,14 \\
\hline 11. & ROI & 90,25 \\
\hline
\end{tabular}

Sumber : Data Primer Diolah Tahun 2017

Berdasarkan Tabel 3 diatas, rata-rata biaya tetap yang dikeluarkan dalam usahatani cabai rawit ini adalah sebesar $\mathrm{Rp}$. 2.014.650,00. Biaya tetap ini meliputi biaya pembelian alat-alat pertanaian, seperti cangkul, alat semprot, gembor dan sewa lahan. Biaya tetap adalah biaya yang tetap dikeluarkan selama produksi dan tidak habis dalam satu kali produksi serta tidak mempengaruhi jumlah produksi. Hal ini diperkuat dengan pendapat Soekartawi et al. (1986), yang menyatakan bahwa biaya tetap adalah biaya yang tidak ada kaitannya dengan jumlah barang yang diproduksi. Biaya tetap tidak habis digunakan dalam satu masa produksi
Rata-rata biaya tidak tetap yang dikeluarkan dalam usahatani cabai rawit ini adalah Rp. 4.090.350,00. Biaya tidak tetap yang dikeluarkan dalam usahatani ini meliputi biaya bibit, pupuk, pestisida, mulsa, dan tenaga kerja. Biaya tidak tetap merupakan biaya yang dikeluarkan selama proses produksi dan habis dalam sekali produksi. Biaya tidak tetap ini mempengaruhi jumlah volume produksi, hal ini sesuai dengan pendapat Hernanto (1996), yang menyatakan biaya tidak tetap adalah biaya yang berubah apabila ada sesuatu usahanya berubah. Biaya ini ada apabila ada sesuatu barang yang diproduksi. Apabila volume produksi bertambah maka biaya tidak tetap akan meningkat, sebaliknya 
apabila volume produksi berkurang maka biaya tidak tetap akan menurun.

Rata-rata biaya total yang dikeluarkan dalam usahatani ini adalah sebesar Rp. 6.105.000,00. Biaya total ini merupakan penjumlahan dari biaya tetap dan biaya tidak tetap, atau semua biaya yang dikeluarkan dalam suatu usahatani, hal ini diperkuat dengan pendapat Soekartawi et al. (1986) yang menyatakan bahwa biaya total adalah keseluruhan biaya tetap produksi yang diperoleh dari penjumlahan total biaya tetap dan biaya variabel.

Rata-rata penerimaan yang diterima oleh petani dalam usahatani cabai rawit ini adalah Rp. 11.723.333,33. Penerimaan ini berasal dari hasil kali antara produksi yang dihasilkan dengan harga jual dipasar. Penerimaan dalam usahatani disebut juga pendapatan kotor, karena dalam penerimaan ini tidak mempertimbangkan biaya yang dikeluarkan selama proses produksi, hal ini sesuai dengan pendapat Soekartawi et al. (1986), yang menyatakan pendapatan kotor adalah pendapatan yang diperoleh dari usahatani selama satu periode usahatani, yang diperhitungkan dari hasil penjualan dan pertukaran.

$$
\text { Rata-rata pendapatan yang }
$$
didapatkan dalam usahatani cabai rawit ini adalah sebesar Rp. 5.618.333,33. Pendapatan adalah hasil kurang dari penerimaan dengan semua biaya yang dikeluarkan. Pendapatan disebut juga dengan penerimaan bersih atau keuntungan. Hal ini sesuai dengan pendapat Gujarati (1978), yang menyatakan pendapatan usahatani adalah total penerimaan atau total revenue dikurangi total biaya produksi, sehingga merupakan pendapatan bersih. Menurut Soekartawi et al. (1986), keuntungan bersih usahatani merupakan selisih antara penerimaan total dengan pengeluaran total.

Efisiensi dalam usahatani merupakan suatu upaya untuk mencapai tujuan dengan menggunakan seminimal mungkin atau menggunakan sumberdaya yang optimal untuk mencapai tujuan yang maksimal. R/C Ratio (Revenue Cost Ratio) merupakan tolak ukur efisiensi suatu usaha yang merupakan perbandingan antara penerimaan usaha (Revenue $=\mathrm{R}$ ) dengan total biaya $(C o s t=T C)$. Nilai ratarata $\mathrm{R} / \mathrm{C}$ ratio dalam uasahatani cabai rawit ini adalah 1,90, yang berarti bahwa usahatani tersebut sangat layak atau menguntungkan (efisien), dimana dapat diartikan bahwa setiap biaya produksi yang dikeluarkan pada usahatani cabai sebesar 1,00 maka akan memperoleh penerimaan sebesar Rp. 1,90. Hal ini sesuai dengan pendapat Hernanto (1996), yang menyatakan bahwa apabila nilai $\mathrm{R} / \mathrm{C}>1$, usaha tersebut layak untuk diusahakan.

Break Even Point (BEP) adalah suatu kondisi yang menggambarkan hasil 
usaha tani yang diperoleh sama dengan modal yang dikeluarkan. Dalam kondisi ini, usaha tani yang dilakukan tidak menghasilkan keuntungan dan tidak mengalami kerugian. Perhitungannya dibagi menjadi dua, yaitu BEP untuk volume produksi dan BEP untuk harga produksi.

BEP volume produksi menggambarkan produksi minimal yang harus dicapai dalam usaha tani agar tidak mengalami kerugian. Nilai rata-rata BEP volume produksi pada penelitian ini adalah sebesar 124,14. Ini berarti bahwa usahatani ini layak untuk dilaksanakan karena nilai rata-rata produksi lebih besar dari nilai rata-rata nilai BEP produksi $(238,06>124,14)$. Usahatani cabai rawit ini sudah menguntungkan saat produksi mencapai $124,14 \mathrm{~kg}$.

BEP harga produksi menggambarkan harga terendah dari produk yang dihasilkan. Jika harga pasaran ditingkat petani lebih rendah daripada BEP harga, maka usaha tani akan mengalami kerugian. Harga BEP ini merupakan harga pokok atau harga dasar untuk pengembalian modal. Agar usaha tani untung, maka petani harus menjual produksi diatas harga dasar ini. Nilai ratarata BEP harga produksi pada penelitian ini adalah 26.038,67. Usahatani cabai rawit ini layak untuk dikembangkan karena rata-rata harga jual cabai rawit lebih besar dari BEP harga $(49.000>26.038,67)$. Usahatani cabai rawit ini sudah menguntungkan pada saat cabai rawit dijual dengan rata-rata harga Rp. 49.000., Analisis tingkat efisiensi penggunaan modal atau Return of Investment (ROI) adalah analisis untuk mengetahui keuntungan usaha berkaitan dengan modal yang dikeluarkan. Nilai rata-rata Return of Investment (ROI pada usahatani ini adalah sebesar 90,25. Ini berarti bahwa dari Rp. 100., modal yang dikeluarkan untuk usahatani cabai rawit ini memperoleh keuntungan sebesar Rp. 90,25.,. Berdasarkan nilai Return of Investment (ROI yang diperoleh usaha tani ini sangat efesien dalam penggunaan modalnya dan menguntungkan, hal ini sesuai pendapat Kasmir (2011), yang menyatakan bahwa Return of Investment (ROI merupakan ukuran atau indeks yang menunjukkan seberapa besar laba atau keuntungan yang didapat dari investasi yang ditanam pada perusahaan atau usaha.

\subsubsection{Prospek Pengembangan Usahatani}

\section{Cabai Rawit}

Prospek pengembangan suatu usaha, dapat dilakukan dengan mengetahui kekuatan, peluang, kelemahan dan ancaman yang ada. Berikut ini adalah 
kekuatan, kelemahan, peluang dan rawit di Kecamatan Arut Selatan.

ancaman yang ada pada usahatani cabai

Tabel 4. Faktor Internal Usahatani Cabai Rawit Di Kecamatan Arut Selatan

\begin{tabular}{|l|c|c|c|}
\hline \multicolumn{1}{|c|}{ Uraian } & Bobot & Rating & Skor \\
\hline STRENGTH (KEKUATAN) & & & \\
\hline Lahan & 0,30 & 4 & 1,20 \\
\hline Tenaga Kerja & 0,20 & 3 & 0,60 \\
\hline Sub Total Kekuatan & $\mathbf{0 , 5 0}$ & & $\mathbf{1 , 8 0}$ \\
\hline WEAKNES (KELEMAHAN) & & & \\
\hline Saprodi & 0,20 & 3 & 0,60 \\
\hline Teknologi & 0,30 & 2 & 0,60 \\
\hline Sub Total Kelemahan & $\mathbf{0 , 5 0}$ & & $\mathbf{1 , 2 0}$ \\
\hline TOTAL & $\mathbf{1 , 0 0}$ & & $\mathbf{3 , 0 0}$ \\
\hline
\end{tabular}

Sumber. Data Primer Diolah Tahun 2017

Tabel 5. Faktor Eksternal Usahatani Cabai Rawit Di Kecamatan Arut Selatan

\begin{tabular}{|l|l|l|l|}
\hline \multicolumn{1}{|c|}{ Uraian } & \multicolumn{1}{c|}{ Bobot } & \multicolumn{1}{c|}{ Rating } & Skor \\
\hline OPPORTUNITY (PELUANG) & & & \\
\hline Komoditas Unggulan & 0,18 & 3,00 & 0,54 \\
\hline Permintaan Pasar & 0,32 & 4,00 & 1,28 \\
\hline Sub Total Peluang & $\mathbf{0 , 5 0}$ & & $\mathbf{1 , 8 2}$ \\
\hline THREAT (ANCAMAN) & & & \\
\hline Iklim & 0,25 & 3,00 & 0,75 \\
\hline Fluktuasi harga & 0,25 & 2,00 & 0,50 \\
\hline Sub Total Ancaman & $\mathbf{0 . 5 0}$ & & $\mathbf{1 , 2 5}$ \\
\hline TOTAL & $\mathbf{1 , 0 0}$ & & $\mathbf{3 , 0 7}$ \\
\hline
\end{tabular}

Sumber. Data Primer Diolah Tahun 2017

Berdasarkan Tabel 4 faktor internal yang mempengaruhi pengembangan budidaya cabai rawit adalah lahan, tenaga kerja, saprodi dan teknologi. Lahan dan tenaga merupakan kekuatan dalam pengembangan budidaya cabai rawit, sedangkan saprodi dan teknologi merupakan kelemahan dalam pengembangan budidaya cabai rawit. Pada Tabel 5 faktor eksternal yang mempengaruhi pengembangan budidaya cabai rawit adalah komoditas unggulan, permintaan pasar, iklim dan fluktuasi harga. Komoditas unggulan dan permintaan pasar merupakan peluang dari pegembangan budidaya cabai rawit, sedangkan iklim dan fluktuasi harga merupakan ancaman dalam pengembangan budidaya cabai rawit.

Berdasarkan Tabel 4 dan 5, selisih antara kekuatan dan kelemahan (1,80-1,20 $=0,60)$ dijadikan sebagai sumbu $X$, sedangkan selisih antara peluang dan ancaman $(1,82-1,25=0,60)$ dijadikan sebagai sumbu Y. Setelah mengetahui nilai pada sumbu $\mathrm{X}(0,60)$ dan sumbu $\mathrm{Y}$ 
(0,60), dimasukkan kedalam matriks pengembangan budidaya cabai rawit di SWOT. Berikut adalah matriks SWOT Kecamatan Arut Selatan.

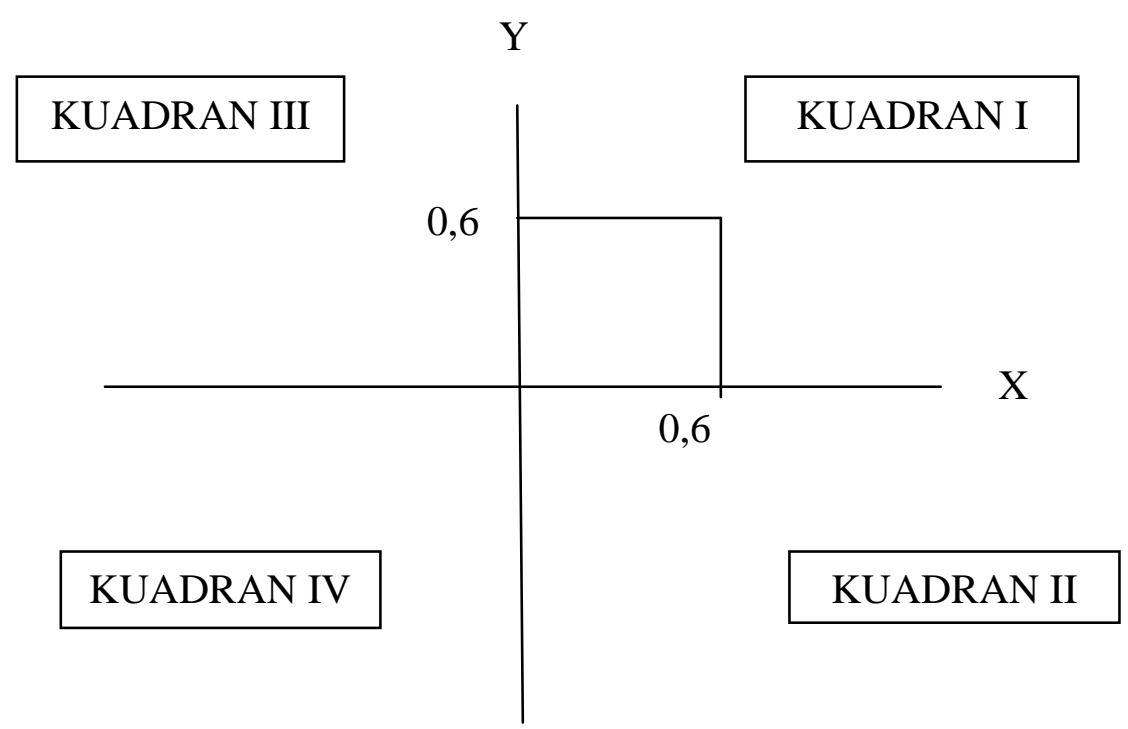

Gambar 4. Matrik SWOT Usahatani Cabai Rawit Di Kecamatan Arut Selatan

Berdasarkan Gambar 4 matriks SWOT usahatani cabai rawit di Kecamatan Arut Selatan posisinya berada pada kuadran (I) satu. Pada kuadran (I) satu, berarti bahwa usahatani cabai rawit ini mempunyai prospek untuk dikembangkan di Kecamatan arut Selatan karena mempunyai peluang dan kekuatan yang sangat mendukung. Hasil budidaya cabai rawit ini, mempunyai peluang sebagai komoditas unggulan dan permintaan pasar, karena hasil produksi cabai rawit ini mempunyai nilai jual yang cukup menjanjikan, tidak memerlukan lahan yang luas, tenaga kerja yang mencukupi dan hasil produksi yang selalu terserap dipasaran. Hal ini sesuai dengan pendapat Rangkuti (2013), yang menyatakan bahwa pada kuadran I, merupakan situasi yang sangat menguntungkan bagi perusahaan. Perusahaan tersebut memiliki peluang dan kekuatan yang sangat besar sehingga dapat memanfaatkan peluang yang ada.

\section{KESIMPULAN}

Berdasarkan hasil pembahasan, dapat diambil kesimpulan sebagai berikut : 1. Hasil analisis usahatani cabai rawit di Kecamatan Arut Selatan mempunyai nilai penerimaan sebesar Rp. 11.723.333,33.,; pendapatan sebesar Rp. 5.618.333,33.,; revenue cost ratio $(R / C)$ sebesar 1.90; break even poin (BEP) produksi sebesar $124,14 \mathrm{~kg}$; break even poin (BEP) harga sebesar Rp. 
26.038,27 dan return on investment (ROI) sebesar 90,25\%.

2. Prospek pengembangan usahatani cabai rawit di Kecamatan Arut Selatan mempunyai prospek yang bagus, karena berdasarkan analisis SWOT berada pada kuadran I yang berarti sangat menguntungkan bagi suatu usaha, dimana mempunyai kekuatan dan peluang yang saling mendukung.

\section{SARAN}

Dengan mengetahui prospek pengembangan budidaya cabai rawit yang bagus di Kecamatan Arut Selatan, perlu dikembangkan budidaya cabai rawit dan dilakukan penelitian lanjutan untuk kecamatan-kecamatan disekitarnya, sehinga diharapkan Kabupaten Kotawaringin Barat menjadi produsen/penyuplai cabai rawit untuk kabupaten sekitarnya.

\section{DAFTAR PUSTAKA}

Badan Pusat Statistik (BPS), 2016. Kotawaringin Barat Dalam Angka Tahun 2016. Kabupaten Kotawaringin Barat.

Cahyono, Bambang, 2007. Cabai Rawit: Teknik Budidaya dan Analisis Usahatani. Kanisius. Yogyakarta

Djuwari, 1993. Ilmu Usaha Tani. Penebar Swadaya, Jakarta.

Gujarati. 1993. Ilmu Usaha Tani. Penebar Swadaya, Jakarta.
Hadisapoetra, S. 1983. Biaya dan Pendapatan di Dalam Usahatani. Departemen Ekonomi Pertanian, Universitas Gadjah Mada. Yogyakarta.

Hernanto, F. 1996. Ilmu Usaha Tani, Penebar Swadaya, Jakarta

http://disperindag.kotawaringinbaratkab.go.id/ detail/infografis-fluktuasi-harga-cabaisepanjang-tahun-2014-2015. Diakses pada Tanggal 5 April 2017

http://www.borneonews.co.id/berita/43750 -musim-hujan-harga-cabai-dipangkalan-bun-makin-pedas. Diakses pada Tanggal 5 April 2017 https://www.harianidn.com/berita/hargacabai-rawit-di-daerah-ini-merokettembus-rp150-ribukg. Diakses pada Tanggal 5 April 2017

Kasmir, 2011. Analisis Laporan Keuangan. Raja Grafindo. Jakarta Kotler, Philip, dan Armstrong, 2004, Dasar-dasar Pemasaran, Edisi Kesembilan, PT. Indeks, Jakarta.

Moekasan Tonny K, Laksiminiwati Purbaningrum, Witono Adiyoga, dan Herman de Putter. 2014. Panduan Praktis Budidaya Cabai. Penebar Swadaya. Jakarta.

Mubyarto, 1991. Pengantar Ekonomi Pertanian. LP3ES, Jakarta.

Rangkuti, Freddy 2013. Analisis SWOT: Teknik Membedah Kasus Bisnis. Gramedia Pustaka Utama. Jakarta.

Soekartawi, Soeharjo. A, John L. Dillon, dan J Hardaker, 1986. IlmuUsahatani dan Penelitian untuk Pengembangan Petani kecil. Universitas Indonesia, Jakarta.

Suryatana, Erwin, 2014. Lebih Memahami Analisis SWOT Dalam Bisnis. Kata Pena. Jakarta.

Stanton, William. J, 2000, Prinsip Pemasaran, Edisi Revisi, Erlangga, Jakarta. 